\title{
Parameter Estimation of Single and Decentralized Control Systems Using Pulse Response Data
}

\author{
Eduard Cheres* and Lev Podshivalov

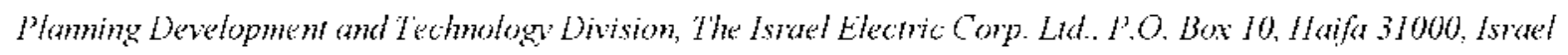 \\ Received Febramy 24, 2002
}

\begin{abstract}
The One Pass Method (OPM) previously presented for the identification of single input single output șstems is used 10 estimate the parameters of a Decentralized Control System (DCS). The OPM is a linear and therelore a simple estimation method. All of the calculations are perfomed in one pass, and no initial parameter guess, iteration, or powerlul starch methends are required. These features are ol interest especially when the parameters ol multi input-output model are estimaled. The benelits of the OPM are revealed by comparing its results against those of two recently published methods based on pulse testing. The comparison is pertomed using two databases from the literature. These datahases include single and multi inpul-output process transtier lumetions and relevant disturbanes. The closed loop responses of these processes are roughly captured by the privious methods, whereas the OPM gives much more aceurate results. If the paramelers of a DCS are Lstimated, the OPM y ields the same results in multi or single structure implementation. This is a novel feature; "1hich indicates that the OPM is a convenient and practice method for the paraneter estimation of nultivariable DCSS
\end{abstract}

Key Words : l'arameter estimation. lime delay, Least squares estimation, Linear algorithm, Decentralized control svistem

\section{Introduction}

Identification of transfer functions models is required for the tuning and design of controllers. For this purpose. a model of the process is assumed and its paramelers are craluated from a test response data. It has becn recognized ${ }^{l}$ that most process dy namics may in general be simplificd by the first order plus dead time (FOPDT) model as:

$$
G(s)=\frac{k_{m s} e^{n / h_{3}}}{b s+1}: k_{m}>0
$$

or by the second order plus dead time (SOPDT) model as:

$$
G(s)=\frac{k_{m} e^{n h}}{a s^{2}+b s+1}: k_{m}>0
$$

Thus many estimation methods are found in the litcrature for the parameter estimation (PE) of FOPDT and SOPDT models. "To cnlance the accuracy of the results nonlinear search algorithms are used. But this partially preicnts their usage as on-line and on site method. Morcover. it has been recognized that the main problem concened with the delay estimation with prediction error techniques is duc to the multimodal nature of the loss function to be minimized with respec1 to delay: ${ }^{3}$ Thus an incorrect guess may results with inadequate estimation. The problem is nore complicated if one realized that the estimated delay is not necessarily the truc onc. i.e. the one measured directly from the pulse response. but rather one of the four paraneters which minimize the loss function in question.

\footnotetext{
"lo whom correspondenee should be addressed. L-mail: cdi $\hat{\theta}^{\prime}$ ice.co.il
}

Only recently a method which is simple. accurate and frec Trom the above drawbacks was proposed. ${ }^{-1}$ The method is called OPM because the estimation is performed in one pass. The OPM is. to the best of our knowledge. a novel application of lincar and non-recursive Least Squared (LS) identification in the frequency domain. ${ }^{56}$

Due to its salient features the results of the OPM were cxicnsiycly compared ${ }^{1-8}$ with other methods. Howerer all of these comparisons were performed using only step response lests. Hence. It is important and interesting to infestigate the OPM results using another popular ies1 signal. A uscful and practical test for obtaining experimental dy mamic data from many chemical engincering processes is pulse testing. This test signal does not generate an outpul offset and the lest time is relatively short. Duc to these features estimation methods using pulse test signal continuously appear in the litcrature. ${ }^{-9}$

Modeling issucs associated with multi-input. multi-oulput (MIMO) systems lave long been a significant focus of attention. Eycn when a proposed MTMO identification is technically sound. casc of use consideration remain a pressing issue to enginecring practice. The coupling between the system loops degrade the identification results. and as a consequence far fewer irnestigation were done for MIMO systcm as compared with single input single outpul onc." Therefore. there is great incentive for developing "simple and conenient" ways to accomplish system identification and subsequent control design when the intended application is multivariable control. ${ }^{\text {de }}$ In this content the application of the OPM to MIMO systems with decentralized controllers is incestigated.

We compare the results of the OPM with those of two state 
of the art methods. These two methods are applied in open and closed loop structures and were especially designed for pulse response data. The bases for the comparison are composed of four single input single output (SISO) dynamics and one MIMO process. ${ }^{2.9}$ Thus the perfonmances of the OPM with pulse data response and MIMO/SISO structures are thorouglily inrestigated in this paper.

The paper is organized as follows. In the next section the OPM is derived and the state of the ant methods based on pulse testing are briefly presented. The comparison between the methods is carried out in open loop and with four representative SISO dynamics. The results of the estimation of the parameters of a MIMO DCS model are presented next. and finally the last section deals with the conclusions.

\section{OPM Parameter Estimation}

We rewrite the SOPDT model in the frequency domain as:

$$
G(j \omega)=\frac{k_{m} e^{j \omega h t}}{1-a \omega^{2}+j b \omega}
$$

Thus the LS estimator of the squared amplitude is:

$$
\left.J_{i i}=\left.\sum_{\omega}|| f(j \omega)\right|^{2}-|G(j \omega)|^{2}\right]^{2}
$$

where: $f(j \omega)$ is the frequency response data, which is calculated from the pulse test time response.

After some modification one obtains:

$$
J_{.4}=\sum_{s, y}\left[|f(j \omega)|^{2}-\frac{1}{\frac{a^{2}}{k_{m}^{2}} \omega^{+}+\frac{b^{2}-2 a}{k_{m}^{2}} \omega^{2}+\frac{1}{k_{m}^{2}}}\right]^{2}
$$

The following substitution of variables is now in order:

$$
x=\frac{a^{2}}{k_{m p}^{2}}: u=\frac{b^{2}-2 a}{k_{p t}^{2}}: z=\frac{1}{k_{m}^{2}}
$$

Therefore:

$$
J_{d}=\sum_{\omega}\left[|f(j \omega)|^{2}-\frac{1}{x \omega^{4}+u\left(\omega^{2}+z\right.}\right]^{2}
$$

The estimator is nonlinear in the parameters. To make it linear we follow Ley's idca and multiply each $1 \mathrm{crm}$ in 1 the summation by the denominator of the right land side tenn. The original loss function becomes:

$$
\left.J_{L}=\left.\sum_{(\prime)}\left|x \omega^{4}\right| f(j \omega)\right|^{2}+\| \omega^{2}|f(j \omega)|^{2}+z|f(j \omega)|^{2}-1\right]^{2}
$$

The minimum of the loss function is obtained if the following relations hold:

$$
\frac{\partial J_{L}}{\partial x}=0: \frac{\partial J_{L}}{\partial u}=0: \frac{\partial J_{L}}{\partial z}=0
$$

and these result with the equations:

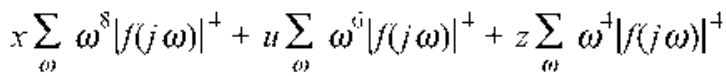

$$
\begin{aligned}
& =\sum_{(1)} \omega^{4}|f(j \omega)|^{2} \\
& x \sum_{\theta()} \omega^{(j}|f(j \omega)|^{+}+u \sum_{b(9)} \omega^{+}|f(j \omega)|^{+}+z \sum_{(t)} \omega^{2}|f(j \omega)|^{+} \\
& =\sum_{\omega} \omega^{2}|f(j \omega)|^{2}
\end{aligned}
$$

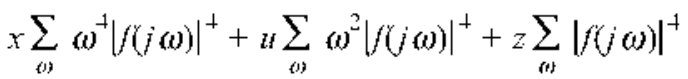

$$
\begin{aligned}
& =\sum_{(n)}|f(j \omega)|^{2}
\end{aligned}
$$

From these lincar cquations $x, u, z$ are obtained and using Eq. (6) we get:

$$
k_{m}=z^{-0.5}: a=k_{m} x^{0.5}: h=\left(u k_{m}^{2}+2 a\right)^{0.5}
$$

A linear LS phase estimator is now defined:

$$
J_{p^{*}}=\sum_{\omega}\left[\arg f(j \omega)+h \omega+\arg \left(1-a \omega^{2}+j h \omega\right)\right]^{2}
$$

And this yields the dead time expression:

$$
h=-\frac{\sum_{t \prime}\left\lfloor\arg f(j \omega)+\arg \left(1-a \omega^{2}+j b \omega\right)\right\rfloor \omega}{\sum_{(1)} \omega^{2}}
$$

Remarks:

1. The method ${ }^{6}$ can be used to generate and calculate the frequency response data.

2. If the identified process is of a higher order the arguments which minimize Eq. (8) do not minimize Eq. (7). In this case the model obtained via the minimization of Eq. (8) is weighted towards the high frequencies. Thus we select the critical frequency as the upper limits for the frequency summation in Eq. (9). This forces the model to be skcwed towards this critical frequency. A novel features if "identification for control" is sought.

3. A fairly pedestrian approach is taken to derive the OPM algorithm for a DCS. The cxtension relay on the linear propertics of the method and is cxplained in details in latier on.

If one follows the same lines as for the second order model and use $a=0$. the following matrix equation is obtained for the FOPDT parameter estimation:

$$
\sum_{(t)}\left[\begin{array}{cc}
\omega^{+}|f(j \omega)|^{+} & \omega^{2}|f(j \omega)|^{+} \\
\omega^{2}|f(j \omega)|^{+} & |f(j \omega)|^{+}
\end{array}\right]\left[\begin{array}{l}
t \\
z
\end{array}\right]=\sum_{\omega}\left[\begin{array}{c}
\omega^{2}|f(j \omega)|^{7} \\
|f(j \omega)|^{2}
\end{array}\right]
$$

$k_{m}$ and $b$ are then calculated from Eq. (10). The dead time estimation is also casily obtained as:

$$
h=-\frac{\sum_{b}\lceil\arg f(j \omega)+\arg (1+j h \omega)\rceil \omega}{\sum_{b(t)} \omega^{2}}
$$




\section{Two Comparative Methods Based on Pulse Response Data}

In order to imvestigate the relative adrantages of the OPM it is compared with the two state of the art methods. The comparison is carried out by a simulation study over a large number of system dynamics, which were previously selected and used for this purpose. All the relevant aspects of the pulse selection and related noise disturbances are already included in the bases and therefore reflected in the simulation results. Thus a full and a compressive study is performed, eliminating the chance that the results are "only a fluke of luck".

In the sequel a brief description of the two state of the art methods is given. For further details the reader is directed to the relevant references. ${ }^{2 \cdot}$

Open Loop Method (OLM). To apply this method, a square pulse is introduced at the process input and a pulse response is recorded in a relatively short time period.

Two points $\left(p_{1}, p_{2}\right)$ of the pulse time response are used in the estimation process. $p_{3}$ is selected as the first peak of the pulse response, whereas $p_{-}$is arbitrarily chosen. The estimation loss function is defined as follows:

$$
J_{O}=\left|p_{1}-p_{1 m}\right|+\left|p_{2}-p_{2 m}\right|+\left|\frac{d}{d l} p_{\beth}(t)-\frac{d}{d l} p_{I_{m}}(t)\right|
$$

The values of the parameters of the model (see Eq. (2)), which minimize the cost given by Eq. (15), are the estimated ones. The minimization is conducted through the MATLAB ${ }^{11}$ function "fmins". Note that the procedure requires initial values of the model parameters. and it is claimed that any reasonable values are good for the initial guess.

Parameter Estimation of a DCS in a Closed Loop Configuration (CLC). This method is applicable for multivariable decentralized systems. It is assumed that the DCSs are well defined for the control structure, therefore no "gain directionality" problem ${ }^{\prime 2}$ is associated with these sy stems.

The estimation test is performed with all of the processes in closed loops. A pulse change is sequentially applied to each set-point while the others are kept constant. The following matrix function is then derived:

$$
\hat{P}=\left[\hat{R} \hat{I}^{1}-\hat{I}\right]^{-1} \hat{C}^{1}
$$

where: $\hat{H}, \hat{P}, \hat{R}, \hat{C}$ are respectively: the Laplace transform of the outputs, the process matrix transfer functions, diagonal matrix of the Laplace transform of pulse set point changes. and diagonal matrix of control matrix transfer functions.

The Fourier transform of Eq. (16) is the "estimation data" These data is used to estimate a matrix model of FOPTD transfer functions. The estimation loss finction is defined for each element $(m . n)$ of the matrix model as follows:

$$
J_{C}(m, n)=\sum_{i-1}^{2}\left|\hat{P}_{m, n}\left(j \omega_{j}\right)-\hat{G}_{m, n}\left(j \omega_{i}\right)\right|
$$

used to find the three model parameters ria the $J_{c}(\mathrm{~m} . \mathrm{n})$ minimization. This is again conducted by the "fmins" function. Again an initial guess of the parameters is required.

\section{Results of Estimation in Open Loops}

Four example processes are used for the performance test of the OPM estimation in open loops, and the results are compared against the OLM ones. The transfer functions of the processes are as follow':

$$
\begin{aligned}
& P_{1}(s)=\frac{e^{-3 s}}{(s+1)^{2}(2 s+1)}: P_{2}(s)=\frac{1}{(s+1)^{5}} ; \\
& P_{3}(s)=\frac{e^{3}}{9 s^{3}+2.4 s+1}: P_{4}(s)=\frac{e^{s}}{\left(2 s^{2}+2 s+1\right)(s+1)}:
\end{aligned}
$$

A common practice is to choose the sampling frequency as 10 to 30 times $^{1.3}$ the equivalent time constant inverse. In this example a synthesis of a proportional, integral and derivative (PID) controller is desired. Since a PID controller can achieve a high bandwidth frequenc, ${ }^{14}$ a sampling rate of 6 cycles/min is selected. A square pulse of a height of $I$ and a width of 1 [min] is applied' to all four-example processes.

With the OLM one has to select an initial guess for the parameters, and the location of the second data point. We take the second point ${ }^{2} p_{2}$ at $t=10[$ min], and try two initial guesses for the estimated parameters (marked 1, 2). We select these initial guesses to be symmetric around the previously estimated values. ${ }^{-}$Our results are designated as $\mathrm{OLM}_{\mathrm{Ll}}$ and $\mathrm{OLM}_{1 \mathrm{l}}$. and are presented in Tables $1-4$. The $\mathrm{n}$ subscript stands for the level of the noise. which is injected at the process output. For the OPM initial conditions are not required. therefore one subscript (n) is sufficient to designate our results with this method.

The estimated models are used in a PID controller synthesis. ${ }^{2}$ Thus the integral of absolute difference (IAD) between the designed closed loop response and the true one is considered as a relevant quality measure for the quality of the PE. The closed loops responses to a combined disturbance and set point unit steps are simulated. and the IADs are calculated up to 25 [min]. The values of the IADs are presented in Table 3 for the $P_{3}(s)$ process.

This process is a tme SOPDT process. and a perfect estimation should lead to a zero IAD in the noise free case. However a difference of $116 \%$ is found between the IADs of the OLMs with a noise level of zero. and a difference of $114 \%$ for the noise level of one. Thus. the OLM results highly depend on the initial guess.

With the OPM we first calculate the open loop frequency ratio for the various noise levels. The process frequency response for pulse input is calculated as follow's":

$$
f(j \omega)=\frac{j \omega \int_{i 1}^{\infty} \cdot(t) e^{j(n) t} d t}{I I\left(1-e^{j(1) D}\right)}
$$

The number of frequency points to be calculated is a 
matter of 'curve fitting' technique. For a second order sy stem three points of the amplitude frequency graph are required to fix the values of the three parameters $\left(k_{m}, a, h\right)$. If noise is present two more frequency points are needed to designate the noise parameters. To be on the safe side the points number is doubled.

Ten points of frequency are then calculated in the interval (0. Critical frequency]. These points are used in Eqs. (9), (10). (12) to calculate the values of the parameters. As stated the $P_{3}(s)$ process is a SOPDT one. therefore the estimation results can be directly compared against the true ones. The $f(j \omega)$ points of this process are depicted in Figure l against the Bode plot of the model. The match is tight and no difference can be observed between the data points and the relevant Bode points of the $\mathrm{OPM}_{1}$ model. It is obvious from the data in Table 3 that the results of the OPM are the closest to the true ones. and are the less sensitive to the noise. In order to emplasize the relative improvement of the OPM as compared with another method (i). we define the relative improvement of the $\mathrm{IAD}$ value as:

$$
\operatorname{RIAD}_{i}=\frac{\mathrm{IAD}_{\mathrm{i}}-\mathrm{IAD}_{\mathrm{OPM}_{\mathrm{i}}}}{\mathrm{IAD}_{\mathrm{j}}}
$$

where $\operatorname{IAD}_{\left(3 \times N_{1}\right.}$ is the closed loop IAD belween the response of the OPM model of rero noise and the true one. The RIADs are compuled and added to Tables 1.2 and 4.

The RIAD values clearly demonstrate the major improvement obtained with the OPM. This is further demonstrated in Figure 2, where the various $P_{1}(s)$ model responses in the closed loop are depicted against the true one. Obviously the $\mathrm{OPM}_{\mathrm{i}}$ response is almost the same as the true one. whereas the OLM ones significantly differ from it. The noise influence can be detected by the RIAD difference belween the 0 noise level case and the 1 noise level. From Tables 1.2 and + the additional axcrage for the OPM is $18 \%$ as compared to an arerage of $81 \%$ for the OLM. For the true SOPDT process the RIAD resolution is very poor. Therefore
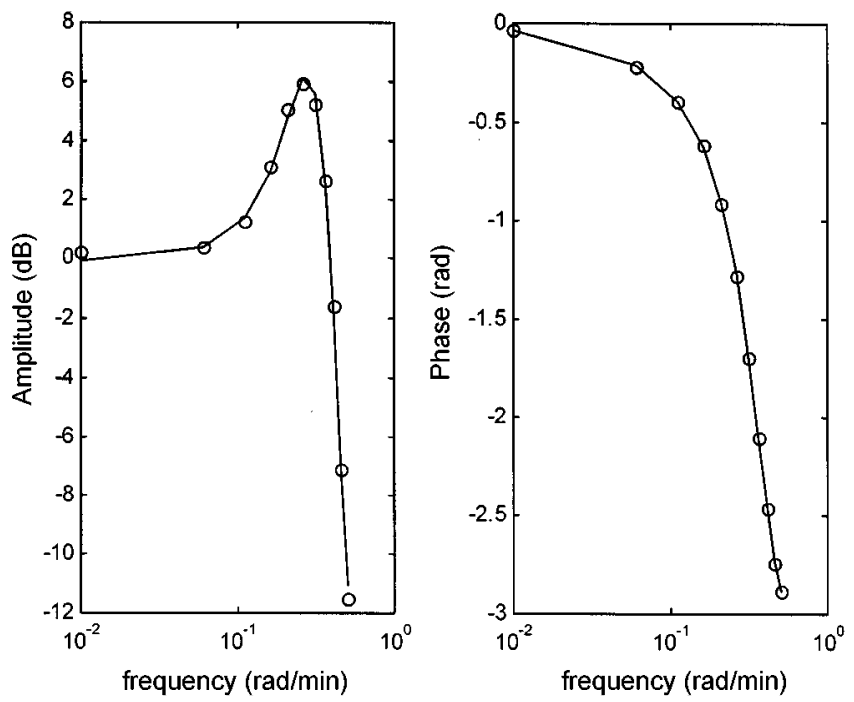

Figure 1. Freguency responlse data points of $P_{3}(s)$ against the Bode plot of its $\mathrm{OPM}_{0}$ model. instead of the RIAD the IAD values are presented in Table 3. Again. the OPM-IAD values are much smaller than the OLM ones.

Table 1. Listimation results of $P_{f}(x)$

\begin{tabular}{lccccccc}
\hline Method & $\begin{array}{r}\text { Noise } \\
\text { I.evel }\end{array}$ & STD & $k_{m}$ & $a$ & $b$ & $h$ & RLAD \\
\hline OLM & 0 & 0 & 0.989 & 1.374 & 2.344 & 2.867 & 97.9 \\
OLM & & & 1.283 & 4.545 & 4.264 & 2.312 & 96.6 \\
OPM & & & 1.000 & 3.181 & 3.505 & 3.503 & 00.0 \\
OLM $_{11}$ & 1 & 0.01 & 1.035 & 2.573 & 3.208 & 1.047 & 98.0 \\
OLM $_{12}$ & & & 0.955 & 2.804 & 3.349 & 4.151 & 95.8 \\
OPM $_{1}$ & & & 0.982 & 3.549 & 3.648 & 3.378 & 23.0 \\
\hline
\end{tabular}

Notes: A. Initial conditions for OI $\mathrm{M}_{\mathrm{nl}}$ are $-k_{m+}-0.5 a-2 h-2$. B. Initial conditions for $\mathrm{OLM}_{\mathrm{n}}$ are $-k_{m}-1.5 a-5 b-4.5 h-4$. C. STD-standard deriation of a Ganusian noise with zero mean. D. RIAD:PID settings $\left(K_{c}-0.931 . J_{1}-4.34 J_{1 J}-1.54\right)$

Table 2. Fstimation results of $P_{2}(s)$

\begin{tabular}{lccccccc}
\hline Method & $\begin{array}{c}\text { Noise } \\
\text { Level }\end{array}$ & STI) & $k_{m}$ & $a$ & $b$ & $h$ & RIAD \\
\hline OLM & 0 & 0 & 0.524 & 1.729 & 2.630 & 0.861 & 81.1 \\
OLM $_{02}$ & & & 0.824 & 2.012 & 3.155 & 2.568 & 70.9 \\
OPM $_{0}$ & & & 0.998 & 3.753 & 3.469 & 1.551 & 0.0 \\
OLM $_{11}$ & 1 & 0.01 & 0.524 & 1.729 & 2.630 & 0.861 & 81.0 \\
OLM $_{12}$ & & & 0.927 & 2.340 & 3.438 & 2.470 & 71.3 \\
OPM & & & 1.010 & 3.785 & 3.566 & 1.506 & 6.3 \\
\hline
\end{tabular}

Notes: $\Lambda$. Initial conditions for OI $\mathrm{M}_{11}$ are $-k_{m}-0.5 a-1.5 b-2 h-1$ B. Initial conditions for OI. $\mathrm{M}_{\mathrm{N}}$ are $-k_{m}-1.5 a-4.5 b-4.5 h-2$. C. RIAD P'ID seltings $\left(\mathrm{K}_{\mathrm{C}}-1.41 . \mathrm{I}_{[}-3.50 . \mathrm{I}_{\mathrm{L}}-1.50\right)$.

Table 3. Listimation results of $P_{3}(s)$

\begin{tabular}{|c|c|c|c|c|c|c|c|}
\hline Method & $\begin{array}{l}\text { Noise } \\
\text { Level }\end{array}$ & SlJ & $k_{n t}$ & $a$ & $h$ & $h$ & I $(\mathrm{I})$ \\
\hline & 0 & 0 & 0.961 & 11.111 & 1.711 & 0.305 & 1.19 .3 \\
\hline ()I. $\mathrm{M}_{02}$ & & & 1.097 & 7.671 & 3.200 & 1.578 & 2.588 \\
\hline$\left(\mathrm{PM}_{0}\right.$ & & & 0.996 & 90019 & $2 . .387$ & 1.002 & 0.022 \\
\hline ()I.M $\mathrm{M}_{\mathrm{l}}$ & 1 & 0.01 & $0.75 ?$ & 7.152 & 1.080 & 0.927 & 1.354 \\
\hline ()I.M $\mathrm{M}_{\mathrm{lz}}$ & & & 1.252 & 7.644 & 3.721 & 1.535 & 2.9013 \\
\hline$\left(\mathrm{OPM}_{\mathrm{l}}\right.$ & & & 0.992 & 9.190 & $2 . .387$ & 0.957 & 0.073 \\
\hline Irue values & & & 1.0000 & 90000 & 2.400 & 10000 & 0.00 \\
\hline
\end{tabular}

Notes: A. Initial conditions for $\mathrm{OLM}_{11}$ are $-k_{m}-0.5 a-6 b-2 h-0.8$. B. Initial conditions for OI $\mathrm{M}_{12}$ arc $-k_{n-1}-1.5 a-12 b-4 h-1.5$. C. IADPID settings $\left(\mathrm{K}_{\mathrm{C}}-1.95, \mathrm{~J}_{1}-3.3 .3 \mathrm{~J}_{\mathrm{D}}-3.02\right)$.

Table 4. Listimation results of $P_{+}(s)$

\begin{tabular}{lccccccc}
\hline $\begin{array}{l}\text { Identilication } \\
\text { Method }\end{array}$ & Joise & STD & $k_{m}$ & $a$ & $b$ & $h$ & RLAD \\
\hline OLM & 0 & 0 & 0.578 & 0.818 & 1.425 & 2.620 & 74.6 \\
OLM & & & 0.437 & 0.251 & 1.097 & 3.014 & 80.2 \\
OPM & & & 0.999 & 2.388 & 2.367 & 1.649 & 00.0 \\
OLM $_{11}$ & 1 & 0.01 & 1.119 & 6.712 & 2.363 & 0.458 & 72.0 \\
OLM $_{12}$ & & & 0.690 & 0.827 & 1.818 & 2.587 & 67.1 \\
OPM $_{1}$ & & & 1.010 & 2.177 & 2.381 & 1.689 & 2.3 .7 \\
\hline
\end{tabular}

Notes: A. Initial conditions for OLM $\mathrm{HII}_{\text {are }}-k_{p 1}-0.5 a-2 b-1 / h-1$. B. Initial conditions tor OI. $\mathrm{M}_{\mathrm{r} 2}$ are $-k_{m}-1.5 a-6 b-4 h-2$. C. RIAD:PID settings $\left(K_{C}-1.15 . I_{L}-2.01 . I_{D}-1.69\right)$ 


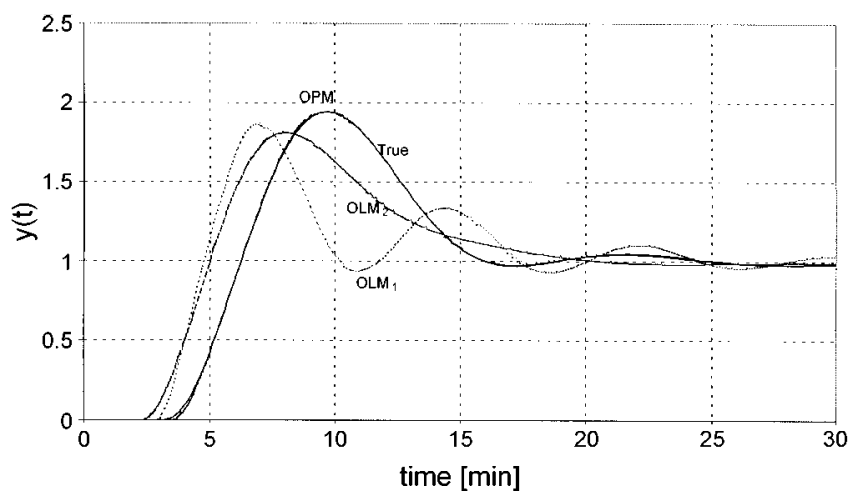

Figure 2. 'lita and estimated closed loop responsess of $P,(s)$ w ith a series PID controller $\left(k_{i}=0.931, \tau_{7}=4.34, \tau_{5}=1.54\right)$.

\section{Results of Estimation in Closed Loops}

The example system is a $3 \times 3$-distillation dy namics. and the process transfer functions are listed in Table 5. The following test procedure is followed. ${ }^{9}$ Firstly. decentralized proportional controllers are applied to the dy namics in closed loops. The proportional gains are $1 .-0.1$ and 1 for loops 1,2 and 3. respectively: Then a rectangular pulse having height of one and width of one [min] is applied to the set point of each control loops one at a time and a sampling rate of 0.1 [min] is used. The CLC procedure is now used to obtain the estimation data at the two frequency points 9.01 and 0.05 [rad/min].

lnstead of minimizing the loss function of $\mathrm{Eq}$. (17) for each system component. we minimize the following global loss function:

$$
J_{C}=\sum_{m, n} J_{C}(m, n)
$$

If the "finins" routine is used to minimize this cost function. it results with negative delays and negative time constants. Therefore an optinization with zero lower bound on the delays and time constants is applied, and is carried out via the MATLAB "constr" function. Two sets of initial conditions are used. and the results are designated $C C_{l}$ and CLC. These results are depicted in Table 5 and the associated initial conditions are presented in Table 6. It can be observed that the $\mathrm{CLC}_{1}$ values for $\hat{P}_{1.3}$ and $\hat{P}_{\text {are }}$ approximately half of those obtained with the CLC 2 . Moreover. using the single estimator of Eq. (17) another values were obtained ${ }^{9}$ for the parameters of the distillation model.

Returning to the OPM, a global amplitude loss function is introduced as follows:

$$
I_{A}=\sum_{m, n} J_{f}(m, n)
$$

where:

$$
J_{i}(m . n)=\sum_{i-1.2}\left\lfloor\left|f_{m . n}\left(j \omega_{i}\right)\right|^{2}-\left|G_{m, n}\left(j \omega_{i}\right)\right|^{2}\right]^{2}
$$

Using the same reasoning a global phase estimator is also easily derived.

Since any system component $(m, n)$ is independent, the linear LS solution of the global estimator of Eq. (22) is exactly the same as the one for the single estimator, i.e the solution of Eqs. (9)-( $(10)$ is repeated for every $(n, n)$ component. The same reasoluing is also true for the solution of the global phase estimator.

The 'estimation data' used with the CLC method is also used with the global OPM estimator, and the estimated parameters are presented in Table 5. Again the OPM results are very close to the true ones (see Table 5 for details). In

\begin{tabular}{|c|c|c|c|c|}
\hline \multirow[t]{2}{*}{ Process } & \multirow[t]{2}{*}{ Aelual } & \multicolumn{3}{|c|}{ Istimated } \\
\hline & & $\mathrm{CLC}_{1}$ & $\mathrm{CLC}_{2}$ & OPM \\
\hline \multirow[t]{2}{*}{$\ddot{p}_{1.1}$} & $0.66 e^{2.0 s}$ & $0.66 e^{2.00 .5}$ & $0.66 e^{2.00 s}$ & $0.66 e^{2.59 s}$ \\
\hline & $\overline{6.7 s+1}$ & $\overline{6.7 s+1}$ & $\overline{6.7 s+1}$ & $\overline{6.7 s+1}$ \\
\hline \multirow[t]{2}{*}{$\ddot{p}_{1.2}$} & $-0.66 e^{3.5}$ & $-0.61 e^{3.515}$ & $-0.61 e^{3 . .518}$ & $-0.61 e^{35 s}$ \\
\hline & $\overline{8.64 s+1}$ & $\overline{8.63 s+1}$ & $\overline{8.63 s+1}$ & $\overline{8.63 s+1}$ \\
\hline \multirow[t]{2}{*}{$\ddot{p}_{1,3}$} & $-0.0049 e^{8}$ & $-0.0048 e^{0.70 s}$ & $-0.005 e^{1 .-10 s}$ & $-0.0049 e^{, 0.90 s}$ \\
\hline & $9.06 s+1$ & $6.49 s+1$ & $\overline{15.18 s+1}$ & $9.06 s+1$ \\
\hline \multirow[t]{2}{*}{$\ddot{P}_{2.1}$} & $1.11 e^{-658}$ & $1.11 e^{-650.5}$ & $1.11 e^{-30.00 s}$ & $1.11 e^{-\langle 3.14)_{5}}$ \\
\hline & $\overline{3.25 s+1}$ & $\overline{3.25 s+1}$ & $\overline{3.25 s+1}$ & $\overline{3.25 s+1}$ \\
\hline \multirow[t]{2}{*}{$\ddot{P}_{2.2}$} & $-2.3 e^{-3.5}$ & $-2.30 e^{-i 00.5}$ & $-2.30 e^{-3.301 .5}$ & $-2.29 e^{-300.5}$ \\
\hline & $\overline{5 s+1}$ & $\overline{500 s+1}$ & $\overline{5.00 s+1}$ & $\overline{4.99 s+1}$ \\
\hline \multirow[t]{2}{*}{$\ddot{P}_{2,3}$} & $-0.01 e^{-12 x}$ & $-0.01 e^{-101.5}$ & $-0.01 e^{e^{-1.33 .5}}$ & $-0.01 e^{-110.5}$ \\
\hline & $\overline{7.09 s+1}$ & $\overline{4.66 s+1}$ & $\overline{1006 s+1}$ & $\overline{7.09 s+1}$ \\
\hline \multirow[t]{2}{*}{$\ddot{P}_{3,1}$} & $-34.68 e^{-412.5}$ & $-34.7 e^{-132.5}$ & $-.34 .7 e^{-(3) 25}$ & $-.34 .68 e^{e^{-10.18 s}}$ \\
\hline & $8.15 s+1$ & $\overline{8.2 s+1}$ & $\overline{8.2 s+1}$ & $8.16 s+1$ \\
\hline \multirow[t]{2}{*}{$\ddot{P}_{3,2}$} & $46.2 e^{-41)}$ & $46.2 e^{-43.5}$ & $46.2 e^{-4.3 .5}$ & $46.24 e^{-4.35 . x}$ \\
\hline & $\overline{10.9 s+1}$ & $\overline{10.95+1}$ & $\overline{10.9 s+1}$ & $\overline{10.93 s+1}$ \\
\hline \multirow[t]{2}{*}{$\ddot{P}_{3,3}$} & $0.89(11.61 .5+1) e^{s}$ & $0.86 e^{-062.5}$ & $0.86 e^{-0102.5}$ & $0.86 e^{-0.02 .5}$ \\
\hline & $\overline{(3.89 s+1)(18.8 s+1)}$ & $\overline{6.83 .5+1}$ & $\overline{6.82 s+1}$ & $\overline{6.5 \% s+1}$ \\
\hline
\end{tabular}
contrast to the previous results no ambiguousness exists

Table 5. Processes and estimated models of a $3 \times 3$ distillation ststem 
Table 6. Initial conditions for the estincation of the distillation system

\begin{tabular}{|c|c|c|}
\hline \multirow[t]{2}{*}{ Process } & \multicolumn{2}{|c|}{ Initial Conditions } \\
\hline & $\mathrm{CLC}_{1}$ & $\mathrm{CLC}_{2}$ \\
\hline$\ddot{P}_{1.1}$ & $\frac{0.3 e^{15}}{3 s+1}$ & $\frac{1 e^{4 s}}{10 s+1}$ \\
\hline$\ddot{p}_{1.2}$ & $\frac{-0.3 e^{-2 s}}{4 s+1}$ & $\frac{-1 e^{-5 s}}{12 s+1}$ \\
\hline$\ddot{P}_{1,3}$ & $\frac{-0.0002 e^{-(0 . .5 y}}{6 s+1}$ & $\frac{-0.007 e^{-1.5 s}}{15 s+1}$ \\
\hline$\ddot{P}_{2,1}$ & $\frac{0.5 e^{3 s}}{1 s+1}$ & $\frac{1.5 e^{10 s}}{5 s+1}$ \\
\hline$P_{2.2}$ & $\frac{-1 e^{-1.5 s}}{2.5 s+1}$ & $\frac{-4 e^{-1.5 s}}{7.5 s+1}$ \\
\hline$P_{2.3}$ & $\frac{-0.005 e^{-0.51 s}}{4 s+1}$ & $\frac{-0.02 e^{-1.5 s}}{10 . s+1}$ \\
\hline$p_{3,1}$ & $\frac{-17 e^{5}}{4 s+1}$ & $\frac{-50 e^{15 s}}{12 s+1}$ \\
\hline$P_{3.2}$ & $\frac{25 k^{-5 s}}{5 s+1}$ & $\frac{60 e^{-15 s}}{15 s+1}$ \\
\hline$P_{3.3}$ & $\frac{0.5 e^{-0.5 s}}{3 x+1}$ & $\frac{1.5 e^{-1.5 s}}{10 x+1}$ \\
\hline
\end{tabular}

between the OPM results which are obtained with the single and global estimators.

\section{Conclusions}

The OPM is cxicnded to the MTMO case and it's results are incstigated and compared against two state of the ant mellods based on pulse testing.

The comparison is performed by a simulation study. To remove the chance that the study results are just "a fluke of luck two comparative test bases from the literature are used. One basis includes four high order SISO dynamics and the second includes a $3 \times 3$ MIMO process with decentralized controllers in closed loops. In all the cases the OPM results are better than those oblaincd with the previous methods. The OPM results are also found to be more robust to the measurement noise.

As differ from the previous melhods. the OPM is lincar and it's results do not depend on an 'initial guess' of the paramelers. Morcover. llic drawback of multiple solutions of the previous melhods is removed. It is also shown that the OPM results for a global MIMO estimator are identical to those of several SISO cstimators. This outcome is unique to the OPM and is nol achicied by am of the previous methods. In other words. a lincar algoritim for the cxplicit solution of the MIMO global estimator is oblained whose calculation burden is cquivalent to the one of an SISO estimator.
These highly facilitated the application of the OPM at the plant floor especially with MIMO systems.

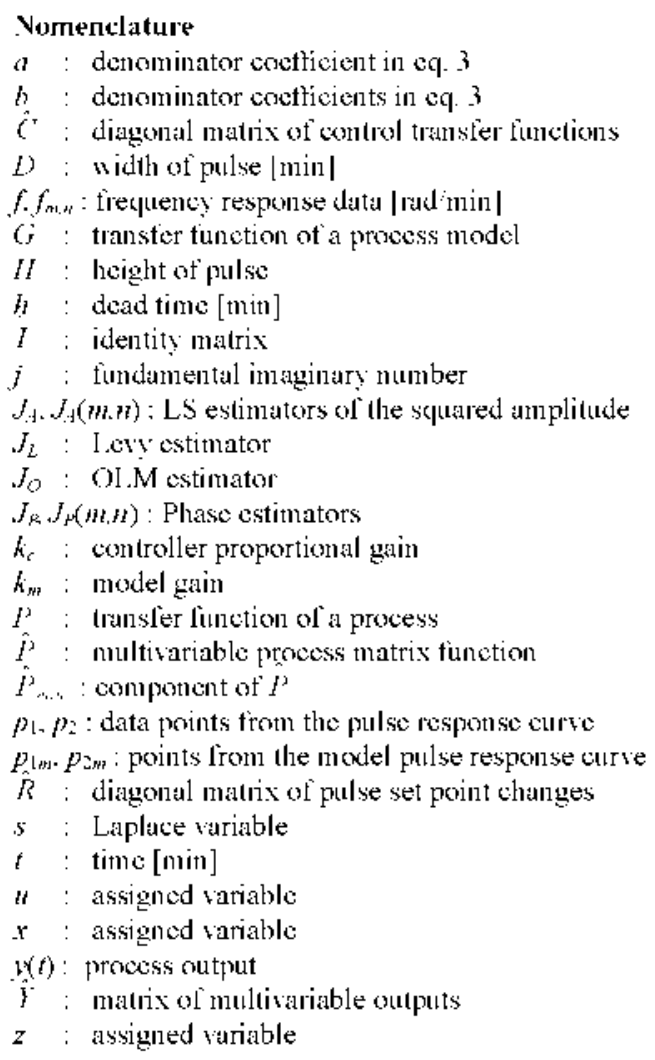

\section{Greek I.etters}

$\omega$ : vector of frequence points [ rad imin]

$\tau_{i)}$ : controller derivative time [min]

$\tau_{j}$ : controller integral time $\mid$ min $\mid$

\section{References}

1. Huang. C.-[a: Chau. C.-I.: Wang. I.-L. J. Chinese Inst. Chem. 1996. 27. 107.

2. IJam, T. W.: Kim, Y. II. Ind Fing. Chem Res 1998, $37,482$.

3. Ferretti. Ci.: Matfezzoni, C.: Scattolini, R. Ltutonatica 1996, 449.

4. Cheres, Г.: Fudelzon, A. Proc of the Fight I. LSTED Int. Conf. Hodelling fdem and Contr: ACTA Press: Calgary. Canada. 1999; p 483 .

5. Schoukens. J.: Pintelon. R. Idenfification of Linear Systems. Perganon: Oxtord. 1991: p 55

6. Tusben. W. I. Process Wodeling Simulation abd Control for Chentcal Frgineers; McGraw-H Iill: Now York, 1990; 505.

7. Cheres. E.: Eydelzon. A. Process Contr and Onatity 1999. 11. 301 .

8. Cheres. E.: Eydelzon. A. Process Contr and Oudin 1999. 11.307.

9. Jam, T. W. Kim, Y. II. .7. Chem. Fing. of Japan 1998, 31.941.

10. Rivera. D. Г... Jum, K. S. ITRT Comtrol Sustems l/agazine 2000. 20.25 .

11. Grace. A. Optimization Toolhor for lise with $M L T L+B$ : The MathWorks Inc.: Natick. U.S.A. 1994: pp 3-16.

12. Li. W. Lee. I. H. $A I C h E J$. 1996. 42. 2813

1.3. T.auzi, M. Proc of the $/ T A / D C$ 1999, 460.

14. Astrom, K. J. Int. J. of idaphive Contr and Sighal Processing $1991,5,3$. 